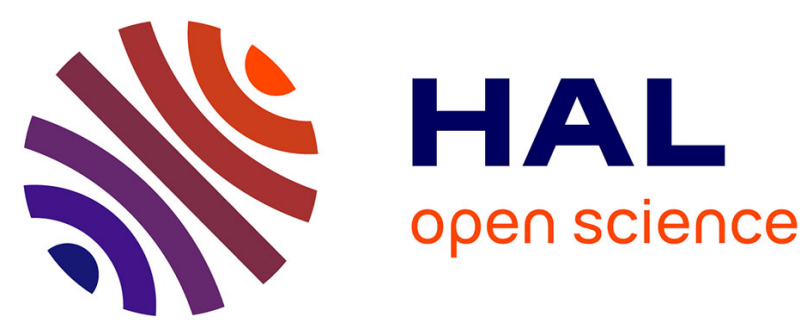

\title{
Criteria for Selecting and Adjusting Ground-Motion Models for Specific Target Regions: Application to Central Europe and Rock Sites
}

Fabrice Cotton, Frank Scherbaum, Julian J Bommer, Hilmar Bungum

\section{- To cite this version:}

Fabrice Cotton, Frank Scherbaum, Julian J Bommer, Hilmar Bungum. Criteria for Selecting and Adjusting Ground-Motion Models for Specific Target Regions: Application to Central Europe and Rock Sites. Journal of Seismology, 2006, pp.137-156. 10.1007/s10950-005-9006-7 . insu-00266153

HAL Id: insu-00266153

https://hal-insu.archives-ouvertes.fr/insu-00266153

Submitted on 21 Jan 2018

HAL is a multi-disciplinary open access archive for the deposit and dissemination of scientific research documents, whether they are published or not. The documents may come from teaching and research institutions in France or abroad, or from public or private research centers.
L'archive ouverte pluridisciplinaire HAL, est destinée au dépôt et à la diffusion de documents scientifiques de niveau recherche, publiés ou non, émanant des établissements d'enseignement et de recherche français ou étrangers, des laboratoires publics ou privés. 


\title{
Criteria for selecting and adjusting ground-motion models for specific target regions: Application to Central Europe and rock sites
}

\author{
Fabrice Cotton ${ }^{1}$, Frank Scherbaum ${ }^{2}$, Julian J. Bommer ${ }^{3} \&$ Hilmar Bungum ${ }^{4}$ \\ ${ }^{1}$ LGIT, Université Joseph Fourier, BP 53, F-38041, Grenoble, France; ${ }^{2}$ Inst. Geowissenschaften, \\ Universität Potsdam, P.O. Box 601553, D-14415, Potsdam, Germany; ${ }^{3}$ Dept. Civil \& Environmental Engineering, \\ Imperial College London, SW7 2AZ, UK; ${ }^{4}$ NORSAR/ICG, P.O. Box 53, 2027 Kjeller, Norway
}

A vital component of any seismic hazard analysis is a model for predicting the expected distribution of ground motions at a site due to possible earthquake scenarios. The limited nature of the datasets from which such models are derived gives rise to epistemic uncertainty in both the median estimates and the associated aleatory variability of these predictive equations. In order to capture this epistemic uncertainty in a seismic hazard analysis, more than one ground-motion prediction equation must be used, and the tool that is currently employed to combine multiple models is the logic tree. Candidate ground-motion models for a logic tree should be selected in order to obtain the smallest possible suite of equations that can capture the expected range of possible ground motions in the target region. This is achieved by starting from a comprehensive list of available equations and then applying criteria for rejecting those considered inappropriate in terms of quality, derivation or applicability. Once the final list of candidate models is established, adjustments must be applied to achieve parameter compatibility. Additional adjustments can also be applied to remove the effect of systematic differences between host and target regions. These procedures are applied to select and adjust ground-motion models for the analysis of seismic hazard at rock sites in West Central Europe. This region is chosen for illustrative purposes particularly because it highlights the issue of using ground-motion models derived from small magnitude earthquakes in the analysis of hazard due to much larger events. Some of the pitfalls of extrapolating ground-motion models from small to large magnitude earthquakes in low seismicity regions are discussed for the selected target region.

Key words: epistemic uncertainty, ground-motion models, logic trees, seismic hazard analysis

\section{Introduction}

The prediction of the expected ground motion and its intrinsic variability at a particular site for earthquake sources with given characteristics is the factor to which seismic hazard is most sensitive. This has been demonstrated, for low exceedance frequencies, by recent seismic hazard analyses for critical facilities, particularly Yucca Mountain (Stepp et al., 2001) and PEGASOS (Abrahamson et al., 2002). Such predictions, usually of acceleration spectral ordinates, are generally performed using ground-motion models that describe the distribution of expected ground motions as a function of a few independent parameters, such as magnitude, source-to-site distance and site classification. The distribution of expected ground motions described by any one ground-motion model is given in terms of median spectral amplitudes and intrinsic variability, the latter usually referred to as aleatory variability and represented by the standard deviation (sigma) of the logarithmic residuals.

The hazard analyst will never be able to identify a single model that can be taken as consistently predicting correctly the ground motions from the hypothetical future events considered in probabilistic seismic hazard analysis (PSHA), simply because the characteristics of 
these events are, by definition, subject to considerable uncertainty. This is the case even for those few regions with large databases of strong-motion recordings, since the number of source-path-site combinations covered is small compared with the range of scenarios considered in a probabilistic seismic hazard analysis. Therefore, in addition to the aleatory variability in each model there is uncertainty, usually referred to as epistemic (knowledge related), on the median and the sigma value of the model itself. For most regions of the world there is not a large database of indigenous earthquake recordings and therefore the epistemic uncertainty in any model is even greater. In several regions, including many where seismic hazard may be an issue, the lack of native recordings is such that there are no region-specific ground-motion models at all, and consequently larger still epistemic uncertainty.

Given the above, a robust seismic hazard analysis must take into account the multitude of potentially applicable ground-motion models for the region under study. This is currently achieved by using more than one ground-motion model within the framework of a logic-tree approach in which the ground-motion models occupy different branches (Kulkarni et al., 1984). The analyst assigns weights to these branches reflecting the relative confidence in each model (Bommer et al., 2005). The importance of these weights on the hazard results decreases as the number of ground-motion models included in the logic tree increases; recent studies have shown that the definition of these weights can become considerably less important than the actual selection of ground-motion models (Sabetta et al., 2005; Scherbaum et al., 2005). This paper specifically addresses the critical issue of selection of ground-motion models to populate a logic tree for seismic hazard analysis.

Due to the improvement and expansion of strongmotion networks, the number of empirical groundmotion models has increased considerably in the last decade. Douglas (2003) summarizes over 120 studies that have derived equations for the estimation of peak ground acceleration and 80 studies that derived equations for the estimation of response spectral ordinates. Although this large number of published ground-motion models seemingly makes the selection of appropriate models for a particular target area easier for the analyst, in practice this is often not the case, in particular for low-to-moderate seismicity regions. In such areas the logic tree will inevitably include groundmotion models imported from other parts of the world. Then the selection process becomes even more compli- cated since ground-motion models, even if they have been generated from data sets with good coverage of the predictor variables, may poorly predict ground motion in the particular study area, which is referred to as the target region. This arises if there are systematic differences in terms of seismic sources, wave propagation or site response between the target region and the host region from where the data used to derive the model was obtained. If such differences between host and target regions are identified, as will be the case for at least some of the models in a logic tree, the analyst has two options, either simply to accommodate these differences through the weighting strategy or to follow the proposition of Campbell (2003) for host-to-target conversions.

The goal of this paper is to discuss the criteria and procedures for selecting and adjusting suites of groundmotion models for seismic hazard analysis. These issues are illustrated by application to rock sites in a moderate seismicity region comprising eastern France, southwest Germany and northern Switzerland, which is referred to here as West Central Europe (WCE). The choice of this region is for demonstration purposes, since it is an area with few indigenous groundmotion models, but was motivated by the participation of the authors in the PEGASOS project (Abrahamson et al., 2002) in Switzerland, a SSHAC Level 4 PSHA (Budnitz et al., 1997).

\section{Selection of candidate ground-motion models}

Ideally, the ground-motion model selection process should result in the smallest set of independent models that capture, potentially after host-to-target conversion, the analyst's estimate of the range of possible ground motions in the target region. An overview of the complete process by which such a selection may be made is presented in Figure 1.

\subsection{Pre-selection of candidate equations}

For simple practical reasons, e.g. considering the large number of potential candidate models, the selection process will naturally start with the identification of those models which are judged to potentially provide relevant independent information which the analyst wants to include in the logic tree. This is referred to herein as the pre-selection stage, in which all available models are tested against some very general criteria which would justify a rejection from further 


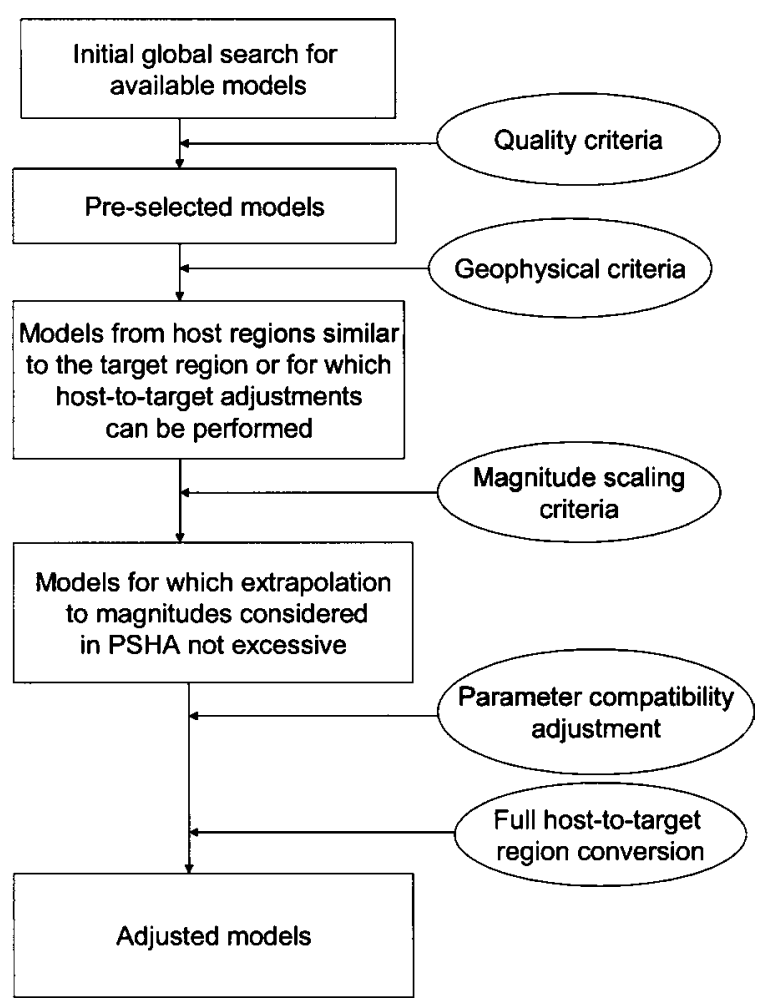

Figure 1. Overview of procedure for the selection of ground-motion models for PSHA.

considerations. The opinion of the authors of this paper is that it is preferable to adopt a procedure whereby reasons must be found for exclusion (i.e., models are innocent until proven guilty) rather than for inclusion because it safeguards against judgments being made on the basis of familiarity with particular regions or particular strong-motion modelers. A case in point is that it might be proposed that seismic hazard analyses for California should include equations derived from Turkish strong-motion records such as Gulkan and Kalkan (2002) and Özbey et al. (2004), which are strongly influenced by the 1999 Kocaeli earthquake. These equations therefore reflect the observed motions from a large magnitude earthquake on the North Anatolian fault which shares many similarities with the San Andreas fault; since there are as yet very few recordings from events of similar size in California, the possibility that the relatively low ground-motion amplitudes observed in Turkey could also occur in the USA should be considered. Following this rejection rather than adoption procedure, however, the analyst must exercise discipline in order to not lose sight of the final goal of the selection to identify the smallest set of indepen- dent models that capture the range of possible ground motions in the region under study.

Assuring the independence of a set of ground motion models, however, is easier said than done in practice. At present, no agreed-upon method exists to judge the degree of dependence resulting from a partial overlap in data sets from which ground-motion models were generated or from similarities of model parameterizations or functional forms. Assuring the exhaustiveness of the model set is an even more open problem. Although it is beyond the scope of this paper to discuss this in detail, it should be noted that this is not purely a philosophical issue. It is directly linked to the problem of whether weights on logic tree branches can be interpreted as probabilities, which down the road affects the whole interpretation of hazard curves. This whole issue has recently been started to be discussed in a number of opinion papers to which we refer the interested reader (Abrahamson and Bommer, 2005; McGuire et al., 2005; Musson, 2005).

The following are criteria that could be considered for rejecting equations from the complete list of available candidate models, arranged in order of descending hierarchy:

1. The model is from a clearly irrelevant tectonic regime.

2. The model is not published in an international peerreviewed journal.

3. The documentation of model and its underlying dataset is insufficient.

4. The model has been superseded by more recent publications.

5. The frequency range of the model is not appropriate for engineering application.

6. The model has an inappropriate functional form.

7. The regression method or regression coefficients are judged to be inappropriate.

The rationale behind these criteria merits some discussion. With regards to criterion [1] it would clearly not be appropriate to use an equation derived for a subduction zone for hazard analysis in a region of crustal seismicity, and vice versa.

Peer review of the candidate equations, specified in criterion [2], is necessary since the peer review process usually ensures that the models are clearly described. The peer review also ensures that basic tests (analysis of residuals, comparison with previous studies) have been performed. Dissemination of a model also favors the detection of mistakes. There have been several examples in the last decade where published ground motion models have been corrected by their authors during 
the review process or after the first candid use of the model. For this reason, models which have been extensively used and tested should be favored. Examples given in the original publication should be reproduced by the users to avoid any mistake in the empirical model implementation. The original dataset used in the study, specified as criterion [3], must be presented in the publication (or another accessible reference) since the seismic hazard process has to be transparent in order to convince decision makers. Moreover, the user needs to have the possibility to check the data quality, so the data processing must be described and the parameters used in the regressions tabulated. This last point is particularly true when corrected analog data are used, and is vital not only for the decision regarding inclusion or exclusion but also for the subsequent weighting strategy. Criterion [4] is also related to publication: if the authors of a particular model have updated their equations, this places an onus on the analyst to use the most recent available model.

Criterion [5] refers to the fact that the usable frequency range of strong-motion accelerograms, particularly those from analog instruments, is limited (e.g. Boore and Bommer, 2005). For engineering applications where high frequencies $(>10 \mathrm{~Hz})$ or low frequencies $(<0.3 \mathrm{~Hz})$ are relevant, ground-motion models derived from analog accelerograms may not provide reliable estimates, even if the authors of the model have presented regression coefficients for such frequencies. However, this may not necessarily be a criterion for rejection since it can be accounted for within the weighting strategy if this is performed considering the relative merits of models in different bins of magnitude, distance and response frequency.

The final criteria, [6] and [7], are somewhat vague but an analyst may consider that a particular model is over- or under-parameterized (the former is more likely), or that for some other reason the functional form is inappropriate. A potentially important point in this respect is the way in which the (possibly nonlinear) magnitude scaling is handled (e.g. Anderson, 1999). Similarly, the analyst may reject the equation if the regression technique is not considered appropriate, such as if the dataset shows a high correlation between magnitude and distance, whence use of a one-stage direct regression will be susceptible to trade-off effects (e.g. Joyner and Boore, 1981; Fukushima and Tanaka, 1990). Other issues that may need to be taken into consideration include the effect of soil non-linearity, which is often not included in the derivation of ground-motion prediction equations. In such cases, if the shape of the attenuation curves is determined from the entire data set then the effect of neglecting nonlinearity in soil response may be to distort the shape of the attenuation function for rock sites.

The resulting set of pre-selected models might be quite different if pre-selection were done based on admittance criteria, by which, loosely speaking, all models are initially assumed to be inappropriate unless proven otherwise. Therefore, the pre-selection should not be treated lightly and its results should be, before proceeding to the next stages of the selection process, critically judged against the selection goal, namely the smallest number of models needed to capture the range of possible future ground motions.

Beyond the pre-selection phase, as indicated in Figure 1, the next stage is to consider geophysical criteria regarding the degree of similarity, or otherwise, between the host regions from where the candidate models have been derived and the target region where the hazard analysis is being calculated. This involves identifying the key parameters that characterize the host and target regions, and then determining reliable values for these parameters, as described in the two following sub-sections.

\subsection{Source properties in host and target regions}

Several aspects are considered relevant regarding the source properties of the target region. In the present context, the so-called stress drop is merely a parameter controlling the high-frequency content of the ground motion. Although the stress drop of individual earthquakes of a given magnitude is believed to be an aleatory variable, mean stress drops are often assumed to be indicative of the tectonic environment: Scholz et al. (1986) suggested that average earthquake stress drops are correlated with deformation rates, related in turn to corresponding differences between fault slip and length (Scholz, 1994). Later studies support this hypothesis, indicating that, for example, ENA (Eastern North America) earthquakes have higher stress drops on average than Western North America earthquakes (e.g. Atkinson, 1996). It should be kept in mind here, however, that the scatter among stress drop estimates for different earthquakes of similar magnitude is also considerable when compared to the regional averages.

The question has been raised as to whether, and if so in which way, the shape of Fourier source spectra seems may be dependent on tectonic environments. For example, it has been suggested that the Fourier spectra observed in ENA feature two corner frequencies 
(Atkinson, 1993; Atkinson and Silva, 1997) as compared to a single corner frequency (Brune, 1970, 1971) in WNA. The suggested two corner-frequency model has, however, been disputed (Haddon, 1996; 1997; 2000; Atkinson, 1996; Atkinson and Boore, 1988; 2000), and this question should not yet be considered resolved. This uncertainty in source spectral shape, affecting in particular larger magnitude and higher frequency ground motions, has clear implications for the host-to-target conversions discussed in this paper.

\subsection{Path and site properties}

\subsubsection{Geometrical spreading}

For simplicity, or because of the shortage of data, geometrical spreading is often approximated as spherical geometrical spreading in attenuation relations (e.g., Atkinson and Boore, 1997) or estimated as a single free parameter of regression, the same for all distances (e.g., Boore et al., 1997). However, the layered structure of the Earth's crust means that the dependence of ground-motion amplitudes on distance may not display a smooth decrease with distance due to the dominance of individual seismic phases over specific distance ranges. Herrmann and Kijko (1983) introduced to this end an 'intuitional' model for Fourier spectral estimates in which the geometrical spreading is spherical out to a distance which often is set at 100 $\mathrm{km}$ (depending on crustal structure and focal depth), and cylindrical beyond.

At close distances (say within $50 \mathrm{~km}$ ) the largest ground motions are caused by waves that travel upwards from the source to the site. As distance from the source increases, the direct wave becomes weaker and the reflection of downgoing waves from interfaces below the source increase in amplitude. Eventually they reach the critical angle and undergo total reflection (Somerville et al., 1990). The large contrast between the crust and the mantle represented by the Moho discontinuity causes these reflections to have large amplitudes. The arrival of these critical reflections beginning at about $50 \mathrm{~km}$ causes the flattening of the attenuation relation out to distances of 100 kilometres or more.

When discussing the geometrical spreading it is worth keeping in mind that strong-motion studies in general are based on a theoretically-based assumption regarding geometrical spreading, leaving whatever remains of the amplitude decay to the anelastic term. This may lead to physically unacceptable results, for example, regressions performed with an assumed $1 / \mathrm{R}$ decay may give a negative $Q$ as found by Berge-Thierry et al. (2003), Ambraseys et al. (1996) and Boore et al. (1997). For this reason alone it makes little sense to extract equivalent $\mathrm{Q}$ values from the anelastic term in a strong-motion equation, since such $\mathrm{Q}$ values would depend more on the spreading model than on the real crustal anelasticity. Weak-motion studies are in principle subjected to the same problems with respect to the geometrical spreading assumptions. In practice they are different in that they usually employ Fourier spectra and moreover cover larger distance ranges, mostly beyond the distance where a cylindrical spreading can be safely assumed for $\mathrm{L}_{\mathrm{g}}$ waves. This provides a more reliable basis for $\mathrm{Q}$ studies from weak motion data, albeit without a simple application to the strong-motion situation. An exception here is the work by Rietbrock et al. (2005), who actually invert independently for both geometrical spreading and Q, based on the Swiss data used by Bay et al. (2003).

\subsubsection{Anelastic attenuation}

Anelastic properties are not considered to be magnitude dependent. The direct use of weak motion results to compare host and target region anelastic properties is, however, difficult. It still remains a challenge to extract this information from direct $S$ waves in a fully satisfactory way and numerous approaches have been suggested for this purpose, all of which have different advantages and drawbacks (e.g. Scherbaum, 1990; Rietbrock, 2001; Bay et al., 2003). Depending on the underlying assumptions, the results are subject to different trade-offs and ambiguities. Hence caution should be exercised in comparing, separately, values of a given stochastic parameter model such as the stress drop or the quality factor obtained from analysis of direct $\mathrm{S}$ waves. In contrast, such problems are less apparent when anelastic attenuation properties are provided through $\mathrm{L}_{\mathrm{g}}$ analysis. The $\mathrm{L}_{\mathrm{g}}$ wave train, interpreted as a superposition of multiply reflected $S$ waves within the crust, is particularly well adapted for attenuation measurements since the $\mathrm{L}_{\mathrm{g}}$ decay does not depend on magnitude but only on crustal attenuation and a particular station response which can be removed.

\subsubsection{Site properties comparison}

Local site conditions at an accelerograph station can dramatically affect the strong ground-motion recorded (e.g Bard and Riepl-Thomas, 1999). The definition of "rock" used in each of the equations is different and hence there is another additional source of incompatibility that needs to be considered within the selection process. The publications in which the equations 
are presented generally include relatively little of the source information on which the site classifications are based, which hampers the interpretation of the defined rock category in each equation. For most of the equations in Table 1, only a range of shear-wave velocities is known for the rock class, a range that moreover often will be a nominal one rather than the actual values encompassed by the data. To overcome the subjectivity of site classifications some studies have used directly measured properties of the ground beneath the accelerograph station. The most commonly used measurement is the near-surface shear-wave velocity $\left(V_{S}\right)$. Shear-wave velocity is usually only measured down to shallow depths so $30 \mathrm{~m}$ is often used as the reference depth to which to compute the average shear-wave velocity $\left(\mathrm{V}_{\mathrm{S} 30}\right)$. Mean values and uncertainty bounds for the $\mathrm{V}_{\mathrm{S} 30}$ of each attenuation model presented in Table 1 have been estimated and are reported in Table 2.

\subsubsection{Host and target region "kappa" properties comparison}

Observations have shown that acceleration spectral density falls off rapidly beyond some maximum frequency. This fall-off at high frequencies has been attributed to near-surface attenuation (Hanks, 1982; Anderson and Hough, 1984) or to source processes (Papageorgiou and Aki, 1983). This distance independent filter, which the authors of this paper interpret to be a site parameter, is taken as $\mathrm{e}^{(-\pi \mathrm{kf})}$ where $\mathrm{f}$ is the frequency. Recent results of Silva et al. (2000) show that there is an approximate correlation between rock quality and near-surface attenuation. This could indicate that the 'shallow site effects' taken into account through the $\mathrm{V}_{\mathrm{S} 30}$ correction may not really be decoupled from 'deeper site effects' which are partially captured by the kappa value. The overall effect of the upper crustal attenuation can be very significant, particularly in regions associated with relatively young rocks. A downhole array in California has identified that over 50\% of the anelastic attenuation occurred in the top $300 \mathrm{~m}$ of the Earth and $90 \%$ in the upper $3 \mathrm{~km}$ (Abercrombie, 1995). In old stable shield regions of Central and Eastern North America, little upper crustal attenuation appears. Microearthquake signals carry important information about attenuation site effects, kappa and stress release in the source region. However, as already discussed, it still remains a challenge to extract this information in a fully satisfactory way and parameters of stochastic models found from weak motions studies may trade off considerably as shown by Scherbaum
(1990) for stress drop against kappa and/or Q. Moreover, a large scatter of the kappa values for a given region has been demonstrated by the analysis of Rietbrock et al. (2006) in Switzerland. In conclusion, it is still difficult to determine and compare kappa values of host and target regions.

\subsection{Selection or rejection of weak motion data models (magnitude scaling criteria)}

Several studies have recently used background seismicity weak-motion recordings for the purpose of producing predictive relationships for the ground motion (e.g. Malagnini et al., 2000 and Bay et al., 2003, both for Europe). These methods are a promising way of estimating ground motion in areas where past recordings from large earthquakes are unavailable since the excitation and the attenuation of these models are calibrated at the regional scale. The general question of to what degree models derived from weak-motion data models could be used for strong-motion prediction is however currently poorly understood and still discussed in the seismological and earthquake engineering communities:

- First, it is still not clear if small and large earthquakes have similar properties with respect to rupture physics.

- Second, there is some evidence that the decay rate of ground motions could be dependent on the magnitude of the causative earthquake.

\subsubsection{Radiated energy vs. magnitude: A scaling issue}

The relation between seismic moment, $M_{0}$, and a length scale, (e.g., square root of the rupture area, rupture length, corner frequency), of earthquakes has been widely used in seismology as a useful gross scaling relation between static parameters. The ratio of the slip to the fault size defines the static stress drop (difference between the final and starting stress levels on the fault). This scaling relation between the moment and the fault area has been shown to be earthquake independent (e.g. Kanamori and Anderson, 1975). For many reasons, however, including assumptions regarding the geometry of the fault plane, the estimate of this static stress drop is in general quite uncertain. Even so, the approximate range $0.1-10 \mathrm{MPa}$ is considered to be robust.

The relation between the radiated energy, $E_{\mathrm{R}}$, and the seismic moment, $M_{0}$, of an earthquake can also 


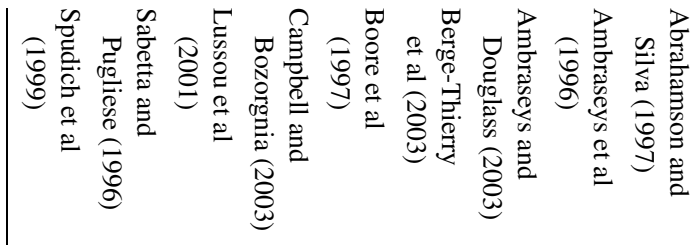

$$
\begin{aligned}
& \begin{array}{lllllll}
3 & 0 \\
3 & 3 & 3 & 3 & 3 & 3 & 3 \\
3 & 3 & 3 & 3
\end{array}
\end{aligned}
$$

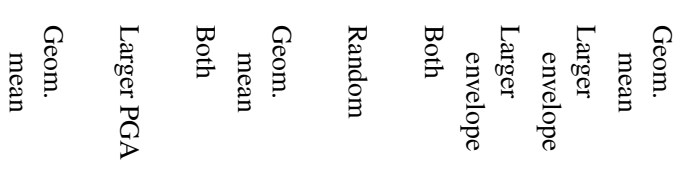

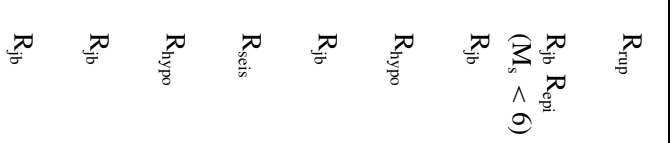

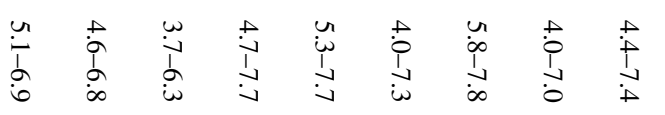

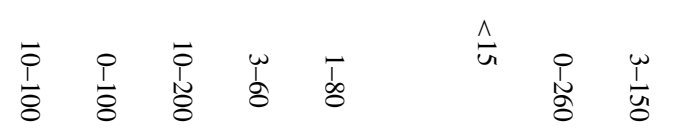

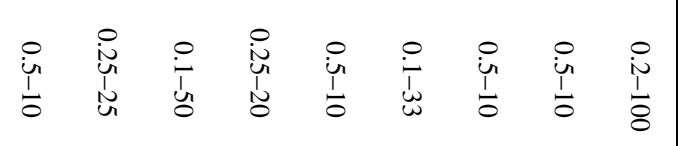

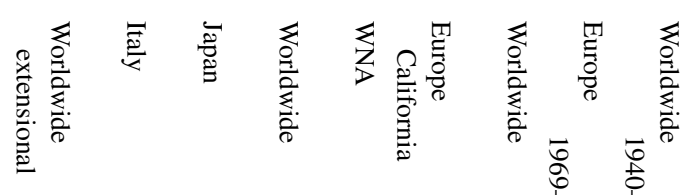

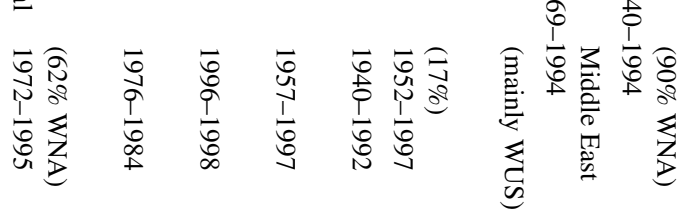

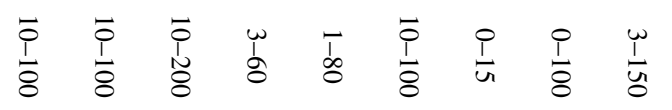

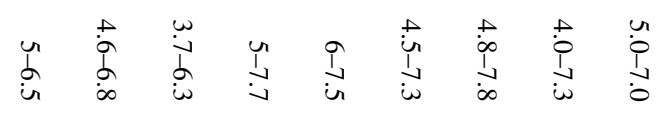

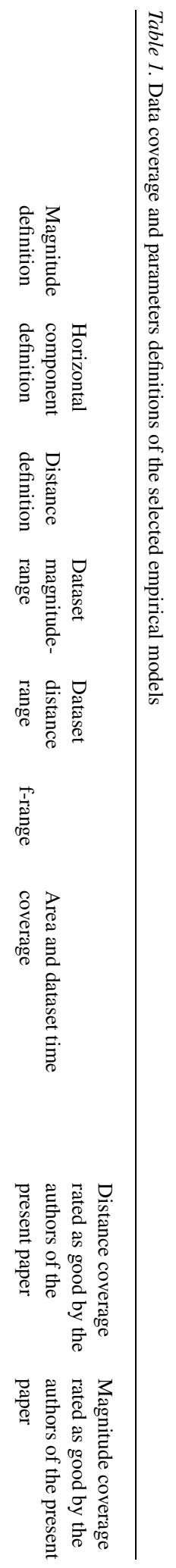


Table 2. Site conditions of the selected empirical models

\begin{tabular}{llcc}
\hline & $\begin{array}{l}\mathrm{V}_{\mathrm{s}, 30} \text { lower } \\
\text { estimate }\end{array}$ & $\begin{array}{l}\mathrm{V}_{\mathrm{s}, 30} \text { best } \\
\text { estimate }\end{array}$ & $\begin{array}{l}\mathrm{V}_{\mathrm{s}, 30} \\
\text { upper estimate }\end{array}$ \\
\hline $\begin{array}{l}\text { Abrahamson and } \\
\quad \text { Silva (1997) }\end{array}$ & 450 & 600 & 900 \\
$\begin{array}{l}\text { Ambraseys et al. (1996) } \\
\text { Ambraseys and }\end{array}$ & 550 & 800 & 1200 \\
$\quad$ Douglas (2003) & 450 & 800 & 1200 \\
$\begin{array}{l}\text { Berge-Thierry et al. (2000) } \\
\text { Boore et al. (1997) }\end{array}$ & 550 & 800 & 1200 \\
$\begin{array}{l}\text { Campbell and Bozorgnia } \\
\quad \text { (2003) }\end{array}$ & 450 & 600 & 750 \\
$\begin{array}{l}\text { Lussou et al. (2001) } \\
\text { Sabetta and Pugliese }\end{array}$ & 350 & 500 & 900 \\
$\quad$ (1996) & 700 & 1000 & 1300 \\
Spudich et al. (1999) & 550 & 800 & 1100 \\
\hline
\end{tabular}

be considered a dynamic scaling relation because the radiated energy reflects the dynamics of faulting. In practice, the ratio $\tilde{e}=E_{\mathrm{R}} / M_{0}$ has long been used in seismology as a useful parameter that characterizes the dynamic properties of an earthquake (Aki, 1966; Wyss and Brune, 1968). When multiplied by rigidity this ratio becomes apparent stress. The ratio can be interpreted as being proportional to the energy radiated per unit area and per unit slip. In many studies, $\tilde{e}$ is found to decrease as the magnitude, $M_{\mathrm{w}}$ decreases. However, because of the large uncertainties in the measurements, whether $\tilde{e}$ is scale independent or not has been vigorously debated (e.g., Ide and Beroza, 2001), and the problem remains unresolved.

Recent improvements in data quality and methodology have, however, significantly improved the accuracy of $E_{\mathrm{R}}$ estimates (e.g. Abercrombie, 1995; Mayeda and Walter, 1996; Izutani and Kanamori, 2001; McGarr and Fletcher, 2002; Boatwright et al., 2002; Venkataraman et al., 2002). The recent results of Kanamori and Rivera (2004) and Oye et al. (2005), despite the large scatter, confirms that the ratio $\tilde{e}$ decreases as the magnitude, $M_{\mathrm{w}}$, decreases. For large earthquakes $\left(M_{\mathrm{w}}=7\right), \tilde{e}$ is approximately $5^{*} 10^{-5}$; but it is approximately a factor of 10 smaller at $M_{\mathrm{w}}=3$ and a factor of 100 smaller at -1 . Recently, Kanamori and Rivera (2004) have investigated the relation between the static scaling relation, $M_{0}$ (seismic moment) versus $f_{0}$ (spectral corner frequency), and the dynamic scaling relation between $M_{0}$ and $E_{\mathrm{R}}$ (radiated energy), suggesting that small and large earthquakes could have significantly different rupture physics prop- erties. Kanamori and Heaton (2000) and Brodsky and Kanamori (2001) explained this scale dependence of energy to moment ratio in terms of friction change. In conclusion, the authors feel that the use of weakmotion data for strong-motion prediction is still an open issue.

\subsubsection{Decay rate vs. magnitude: Another scaling issue}

From recent ground-motion studies there are also some indications that the decay rate of ground-motions could be dependent on the magnitude of the causative earthquake (e.g. Anderson, 2000; Bragato and Slejko, 2005). Recently, Ambraseys et al. (2005) have shown that their data support a decay rate that varies with magnitude, where ground motions from small earthquakes decay more rapidly than ground motions from large earthquakes. Atkinson and Boore (2003) have also adopted magnitude-dependent far-field decay rate for empirical models in subduction zones. Frankel et al. (1990) shows that a steep amplitude decay can be explained by the reflection of the up-going direct wave at the underside of the layers. The geometrical decay should therefore be dependent also on the depth of the earthquake. The fact that geometrical decays could be magnitude dependent is therefore another reason for rejecting groundmotion models if magnitude scenarios are significantly outside the range of the data used to derive the models, the primary reason being the magnitude extrapolation itself.

\subsubsection{Magnitude scaling criteria}

Both the scaling of stress drops and geometrical spreading with magnitude suggest that weak motion models could easily lead to erroneous estimation the ground motions of large earthquakes. These two points are still discussed in the seismological community and no definitive conclusions can be drawn about the use of such weak motion models to predict strong motions. The fact that radiated energy and geometrical decays could be magnitude dependent favors the rejection of ground-motion models if magnitude scenarios are significantly outside the range of the data used to derive the models (magnitude scaling criteria). As a result of these two potential scaling effects, the weak motion models will be difficult to accept within our selection procedure (Figure 1). These weak motion models are, however, essential for host-to-target adjustments. 


\subsection{Requirements for the ground-motion section of a logic tree}

Logic trees have become a popular tool that facilitates taking into account the multitude of models considered applicable for seismic hazard analysis in a particular region. In this context, the weight on each branch-tip reflects the analyst's degree-of-belief in the corresponding model. At first glance, the selection of ground-motion models does not seem to be linked to the interpretation of branch weights in terms of their statistical properties, but it is worth pointing out that this is not completely correct. Whilst it is not a view taken by the authors, it is worth mentioning that in case branch tip weights are interpreted as probabilities of the corresponding models to be true, sometimes referred to as veridical probabilities, the Kolmogoroff axioms require that the corresponding models must span the total model space (exhaustiveness) and are mutually exclusive. Even though it is difficult to achieve in practice, within such a line of thought the selection process has to assure that these conditions are met. If weighting factors are not assumed to be veridical probabilities, the analyst may still want to reduce the effect of inter-dependent models, for example created by overlapping datasets used for the model generation (e.g. Berge-Thierry et al., 2003; Ambraseys et al., 1996) which pragmatically can also be achieved through the weighting strategy. For further discussion of the effects of model dependence on the overall degree-of-belief on ground motion in a composite model framework the reader is referred to Scherbaum et al. (2005).

\section{Adjustments of ground-motion models}

Whenever two or more ground-motion models are combined in a logic tree, there will almost always be incompatibilities amongst the equations; in order for the logic tree to correctly capture the epistemic uncertainty in the ground-motion model, appropriate adjustments need to be made to compensate for the incompatibilities. The first group of adjustments is related to the definitions of ground-motion parameters and independent variables, and these must always be applied. The second group of adjustments corresponds to systematic differences between the host and target regions. These host-to-target adjustments do not necessarily need to be applied, since the analyst may choose instead to accommodate the differences through the weighting strategy applied to the logic-tree branches; herein, however, it is assumed that the analyst will opt for the application of host-to-target adjustments, if possible.

\subsection{Adjustments for parameter compatibility}

There are several options available to strong-motion modelers for the definition of each of the parameters used in ground-motion models. The different definitions will lead to systematic differences between the predicted median values that distort the estimate of the epistemic uncertainty which the models are selected to capture. Adjustments for different parameter definitions therefore must be made in order to achieve compatibility amongst the equations as well as between the equations and the model of seismic sources used in the hazard calculations.

Although regression based on vertical components have been carried out, most studies deal only with the more important (from an engineering point of view) horizontal components. Since there are usually two perpendicular components of recorded horizontal motion, there are different options for combining the motion from the two traces, these including the larger of the two, their geometric mean and the random component. None of these options can be described as being superior to the others; the only important issue is that the selected component definition is consistent with the specification of the seismic loading used in the engineering analysis for which the hazard analysis is being performed. Once the convention for the horizontal motion is chosen for a project, simple scalar adjustments, which vary with response period, can be applied to the median motions from those models based on different definitions (Beyer and Bommer, 2005).

Although ground-motion models increasingly use moment magnitude, $\mathrm{M}_{\mathrm{w}}$, as the measure of earthquake size, several equations are based on other measures, most commonly surface-wave magnitude, $\mathbf{M}_{\mathrm{s}}$, and $\mathrm{M}_{\mathrm{JMA}}$. For this parameter, the choice will be dictated by the magnitude scale in which the earthquake catalogue, and hence the recurrence relationships, are defined, so that there is compatibility between the seismicity and ground-motion models. For those predictive equations in the logic tree that use magnitude scales other than that used for the recurrence relationships, adjustments can be easily made using empirical correlations (Bommer et al., 2005).

Several distance metrics have been used in the derivation of ground-motion models (e.g. Abrahamson and Shedlock, 1997; Reiter, 1990). The distance definition to be used in the hazard calculations will depend 
on the way in which individual earthquake sources are modeled in the hazard software. Incompatibilities will often exist because in many widely used hazard codes the distance definition is implicitly based on point sources (i.e. epicentral or hypocentral distance) whereas most ground-motion models use distance definitions based on extended source models. Moreover, combinations of three or more equations will almost always result in at least two different distance metrics appearing in the logic tree. Scherbaum et al. (2004a) present distance conversion coefficients developed specifically for any given target region based on the distributions of focal depth, rupture mechanism and dip angle. The application of the distance conversions is considerably more complex than the horizontal component and magnitude conversions described above, because they are both magnitude and distance dependent. The distance conversions will often have a greater impact on the resulting median ground motions than the other two conversions together.

The empirical equations used to apply the adjustments for the three parameters discussed above each have an associated aleatory variability. The effect of this variability on the overall aleatory variability in the ground-motion model must be accounted for through the laws of error propagation (Bommer et al., 2005). The variability increase caused by the distance conversion is again much greater than that due to the magnitude conversion, although the latter is generally too large to be neglected.

\subsection{Host-to-target adjustments}

\subsubsection{Style-of-faulting adjustments}

The influence of style-of-faulting (or focal mechanism) on the amplitude of earthquake ground motion is a subject of ongoing research. Whilst there is broad agreement that the motions produced by reverse faulting events are higher, on average, than those from strikeslip earthquakes, the nature and degree of the differences is partially osbcured by the lack of consensus on the classification of different focal mechanisms into generic groups. Bommer et al. (2003) have developed a scheme for introducing style-of-faulting into groundmotion predictions that do not include this parameter.

\subsubsection{Site effects adjustments}

In order to make adjustments to a common site profile or $V_{\mathrm{S} 30}$, as introduced previously, several methods can be applied. One solution here is that simple site conditions adjustments can be made using factors derived from attenuation equations such as Boore et al. (1997). Their adjustments are based on a using the $V_{\mathrm{S} 30}$ velocities directly and not on soil classes, thereby being particularly well suited to adjust for differences defined in terms of site velocity. Generic rock models with $V_{\mathrm{S} 30}$ as a single free parameter can also be used. These generic profiles are characterized by a base rock velocity equal to the target rock velocity and a surface velocity $V_{\mathrm{S} 30}$ equal to the host region velocity. Such models are used to correct for the differences between the sites which are assumed to be representative for the ground-motion models under consideration, and the reference rock site for the target region. We suggest to generate the model set such that for a $V_{\mathrm{S} 30}$ of $620 \mathrm{~m} / \mathrm{s}$ the model matches the Californian rock model (Boore and Joyner, 1997, Table 1) while for $V_{\mathrm{S} 30}$ of $2800 \mathrm{~m} / \mathrm{s}$ it matches the hard rock model for ENA (Boore and Joyner, 1997, Table 2). For each chosen $V_{\mathrm{S} 30}$ rock velocity an interpolation fraction Ifrac $V_{V_{S 30}}$ is defined (in log scale) with respect to $V_{\mathrm{S} 30}$ of the two Boore and Joyner (1997) rock models $\left(V_{\mathrm{S} 30}=620\right.$ and $\left.2800 \mathrm{~m} / \mathrm{s}\right)$ :

$$
\text { Ifrac }_{V_{S 30}}=\frac{\log \left(V_{S 30}\right)-\log (620)}{\log (2800)-\log (620)}
$$

where $V_{\mathrm{S} 30}$ is given in $\mathrm{m} / \mathrm{s}$

The generic models of Boore and Joyner (1997) are anchored at $z_{a}=1,30,190,4000$ and 8000 meters (Table 3). Our generic shear-wave velocities for a given interpolation fraction are then defined at these anchoring depths using the following formula:

$$
\beta_{\mathrm{V}_{\mathrm{S} 30}}\left(\mathrm{Z}_{\mathrm{a}}\right)=10^{\left(\mathrm{Ifrac}_{\mathrm{S} 30} \cdot\left(\log \left(\beta_{\mathrm{za} 2}\right)-\log \left(\beta_{\mathrm{za}}\right)\right)+\log \left(\beta_{\mathrm{za}}\right)\right)}
$$

where $\beta_{\mathrm{za} 2}$ and $\beta_{\mathrm{za} 1}$ are the values of Boore and Joyner (1997) rock models at the anchoring depths (Table 3).

Finally, in each depth segment (between two anchoring depths) the generic model shear wave velocities are represented by a power law model which goes through the velocities at the anchoring depths defined in Equation (2). For each segment, the velocity is de-

Table 3. Rock models of Boore and Joyner (1997)

\begin{tabular}{lrrrrr}
\hline za & $1 \mathrm{~m}$ & $30 \mathrm{~m}$ & 190 & 4000 & 8000 \\
\hline$\beta_{z a 1}$ & 336 & 850 & 1800 & 3300 & 3500 \\
$\beta_{z a 2}$ & 2768 & 2791 & 2914 & 3570 & 3600 \\
\hline
\end{tabular}


Table 4. $\beta_{0}$ and $p_{0}$ values for several $\mathrm{V}_{s 30}$ and depth ranges

\begin{tabular}{lcccccc}
\hline $\mathrm{z}$ & $0-1 \mathrm{~m}$ & $1-30 \mathrm{~m}$ & $30-190$ & $190-4000$ & $4000-8000$ & $>8000$ \\
\hline$\beta_{0}(600 \mathrm{~m} / \mathrm{s})$ & 232.48 & 322.12 & 830.03 & 1782.74 & 3294.81 & 3498.03 \\
$p_{0}(600 \mathrm{~m} / \mathrm{s})$ & 0. & 0.278 & 0.414 & 0.202 & 0.086 & 0. \\
$\beta_{0}(900 \mathrm{~m} / \mathrm{s})$ & 444.54 & 560.72 & 1134.52 & 2023.40 & 3363.63 & 3524.02 \\
$p_{0}(900 \mathrm{~m} / \mathrm{s})$ & 0. & 0.207 & 0.313 & 0.167 & 0.067 & 0 \\
$\beta_{0}(1200 \mathrm{~m} / \mathrm{s})$ & 705.59 & 835.99 & 1421.03 & 2216.69 & 3414.11 & 3542.88 \\
$p_{0}(1200 \mathrm{~m} / \mathrm{s})$ & 0. & 0.156 & 0.241 & 0.142 & 0.05 & 0. \\
$\beta_{0}(1500 \mathrm{~m} / \mathrm{s})$ & 1011.13 & 1143.56 & 1695.57 & 2381.15 & 3454.23 & 3557.74 \\
$p_{0}(1500 \mathrm{~m} / \mathrm{s})$ & 0. & 0.116 & 0.184 & 0.122 & 0.043 & 0. \\
$\beta_{0}(1800 \mathrm{~m} / \mathrm{s})$ & 1358 & 1480.52 & 1961.31 & 2525.86 & 2487.66 & 2815.80 \\
$p_{0}(1800 \mathrm{~m} / \mathrm{s})$ & 0. & 0.082 & 0.137 & 0.106 & 0.034 & 0. \\
$\beta_{0}(2100 \mathrm{~m} / \mathrm{s})$ & 1744.22 & 1844.71 & 2220.23 & 2656.00 & 3516.38 & 3580.54 \\
$p_{0}(2100 \mathrm{~m} / \mathrm{s})$ & 0. & 0.054 & 0.0970 & 0.009 & 0.026 & 0. \\
$\beta_{0}(2400 \mathrm{~m} / \mathrm{s})$ & 2627.11 & 2648.54 & 2722.44 & 2884.78 & 3564.13 & 3597.88 \\
$p_{0}(2400 \mathrm{~m} / \mathrm{s})$ & 0. & 0.008 & 0.003 & 0.069 & 0.014 & 0. \\
$\beta_{0}(2700 \mathrm{~m} / \mathrm{s})$ & 2627.11 & 2648.54 & 2722.44 & 2884.78 & 3564.13 & 3597.88 \\
$p_{0}(2700 \mathrm{~m} / \mathrm{s})$ & 0. & 0.008 & 0.003 & 0.069 & 0.014 & 0. \\
\hline
\end{tabular}

scribed by the following equation:

$$
\beta_{\mathrm{V}_{\mathrm{S} 30}}(\mathrm{z})=\beta_{0}\left(\mathrm{~V}_{\mathrm{S} 30}, \mathrm{z}\right) \cdot \mathrm{z}^{\mathrm{p}_{0}\left(\mathrm{~V}_{\mathrm{S} 30}, \mathrm{z}\right)}
$$

Table 4 gives the values of $\beta_{0}$ and $p_{0}$ for several $V_{\mathrm{S} 30}$ and depth ranges. Figures 2 and 3 show velocitydepth models and corresponding site amplification functions, respectively, captured by this model for $V_{\mathrm{S} 30}$ values of $600,900,1200,1500,1800,2100,2400$, $2700 \mathrm{~m} / \mathrm{s}$

Since these generic rock profiles are rather smooth ( $\mathrm{V}_{\mathrm{S}}$ increasing slowly with depth), it is also possible to consider some more realistic rough profiles based on site investigations. However, the availability of site velocity profiles near strong-motion stations is still poor and the total number of such profiles available for the European region is limited (Rey et al., 2002). The correction factors for adjustments to a reference site velocity of $650 \mathrm{~m} / \mathrm{s}$ on the predicted spectra are illustrated in Figure 4 (top).

\subsubsection{Full host-to-target geophysical adjustments}

Empirical ground-motion models, even if they are based on good data sets in terms of magnitude, distance and frequency coverage, may still perform poorly for a particular region if strong systematic differences exist between the target region and the host region of the ground-motion model (GMM)
Shear Wave Velocity, $\mathrm{km} / \mathrm{s}$

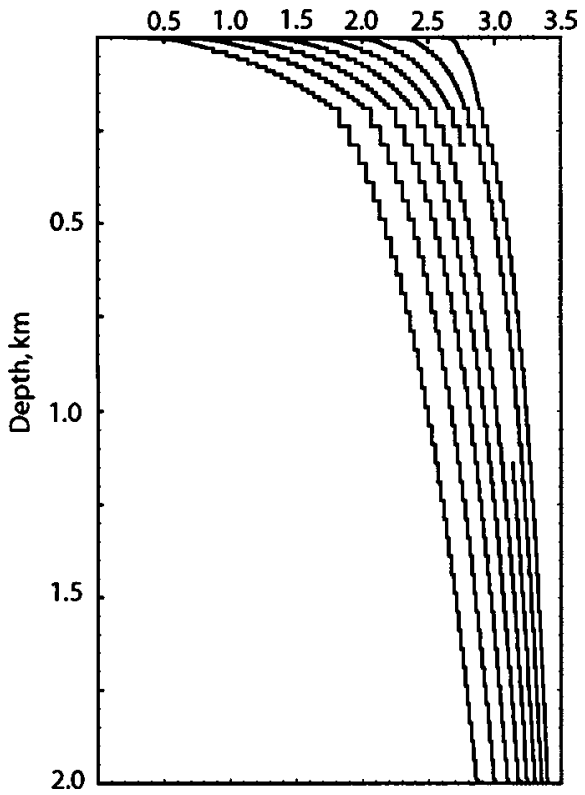

Figure 2. Generic single parameters rock site models to be used for site conversions ( $V_{\mathrm{S} 30}$ values of $600,900,1200,1500,1800,2100$, $2400,2700 \mathrm{~m} / \mathrm{s})$.

regarding the properties of wave propagation and source properties. These differences can, however, be corrected for, and one way to do this is based on the idea of the hybrid empirical approach of 


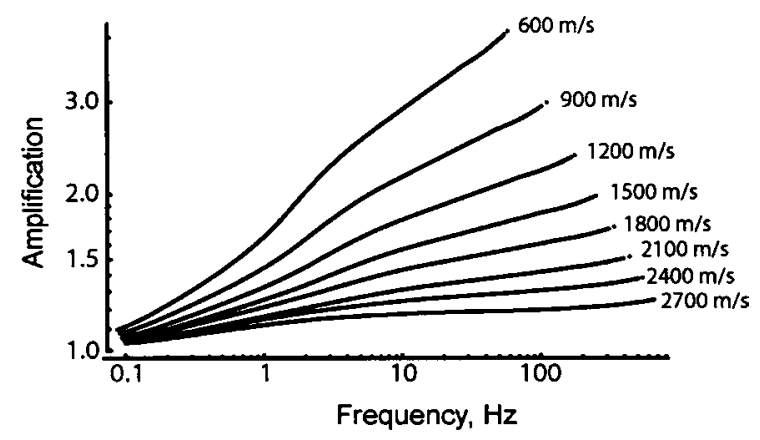

Figure 3. Site amplification functions (surface over half-space motion) for the generic rock models shown in Figure 2 calculated by the quarter-wavelength approach as described by Boore (2003a, Equations (11) to (18)).

Campbell (2003), connecting host and target regions through stochastic predictions based on Random Vibration Theory, RVT (Boore and Joyner, 1984; Boore, 2003a).

Both for the host and the target region, several authors (e.g. Boore, 1983; Raoof et al., 1999; Malagnini et al., 2000; Bay et al., 2003; Rietbrock et al., 2006) have used seismograms of background seismicity and RVT (Boore, 1983; Boore and Joyner, 1984) to derive stochastic models of ground motion. As suggested by Campbell (2003), these stochastic models can be used to generate response spectral correction filters for each ground-motion model to account for differences in source, path and site parameters between host and target regions (see also Scherbaum et al., 2005). The hostto-target conversion factors are equal to the ratio between the response spectral ground motions estimated using the stochastic method (Boore, 1983) for the target region and the host region. In order to apply the stochastic method for the calculation of these conversion factors a number of parameters need to be defined for the target region. These parameters include (e.g. Boore, $2003 a, b)$ type of source spectrum, stress drop $(\Delta \sigma)$, geometric attenuation, source duration, path duration, path attenuation, shear-wave velocity at the source, density at the source, local site diminution, and a local shear-wave velocity and density profile at the site. Reference models in terms of these parameters have to be specified for each GMM as well as for the target region.

Response spectra in the host and target can be obtained via time domain simulation or directly using RVT theory. In essence, RVT provides an estimate of the ratio between peak motion and rms motion, and Parseval's theorem is then used to obtain the

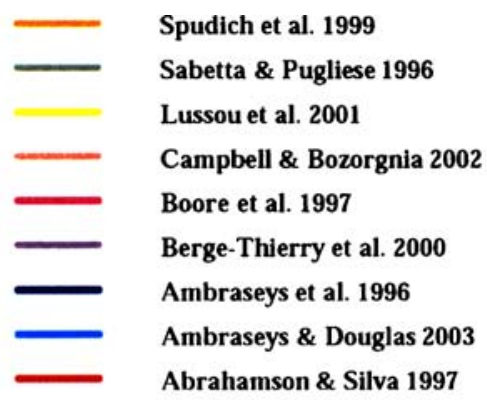

Vs30 adjustment factor

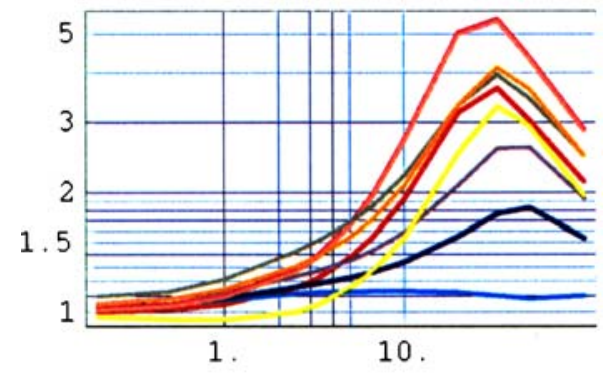

Vs30 and kappa adjustment factor

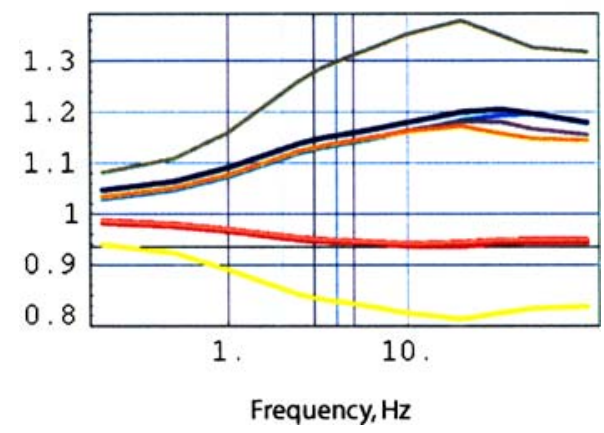

Figure 4. Adjustment factors. (top) $\mathrm{V}_{\mathrm{S} 30}$ adjustment factors using generic rock models. Host region $\mathrm{V}_{\mathrm{S} 30}$ velocities are described in Table 2 (best estimate values). The target velocity is equal to 650 $\mathrm{m} / \mathrm{s}$. (bottom) $\mathrm{V}_{\mathrm{S} 30}$ and kappa adjustment factors; host region parameters are described in Table 5. The target kappa value is equal to $0.0125 \mathrm{~s}$.

rms motion in terms of an integral of the squared amplitude spectrum. The ratio between peak motion and $r m s$ motion is then calculated using the number of cycles of quasi-stationary motion of the oscillator. This number depends on ground-motion duration and oscillator damping. The response spectral transfer functions are hence dependent on attenuation and time-history duration difference between the host and the target region, and they are different from Fourier transfer function used, for example, in site response analysis. 


\section{Application to the West Central Europe (WCE) region}

West Central Europe (WCE) comprises eastern France, southwest Germany and northern Switzerland, and is introduced here for illustration purposes.

\subsection{Selection of ground-motion models}

\subsubsection{Target region source properties}

Slip and deformation rates in the Alpine area are less than $1 \mathrm{~mm} /$ year (e.g. Vigny et al., 2002). North of the Western Mediterranean, Western Europe is a continental domain, part of the Eurasian plate, where significant active deformation is restricted to a few structures such as the Rhine graben. Recent results of Nocquet et al. (2003) show that intraplate deformation and fault slip rates in active tectonic structures such as the Rhine Graben and the western Alps are still below the accuracy $(1 \mathrm{~mm} / \mathrm{year})$ of current space geodetic techniques. Recent paleoseismic studies (e.g. Ferry et al., 2005) suggest active extensions of 1-1.5 mm/year within the lower and the upper Rhine Graben structures.

According to the Scholz et al. (1986) classification, the Alps, the Jura and the Rhine Graben constitute a plate boundary related area, while the Alpine Foreland is an intraplate related area. Since regional average stress drop may increase with average recurrence time, large stress drops - and large variations in stress dropscannot be excluded for WCE. This in turn calls for the use of spectral attenuation relations available for the various types of source properties in order to cover the epistemic uncertainty.

\subsubsection{Target region path properties}

In the target region, Moho depth increases with distance from the Alpine chain, from 25 to $30 \mathrm{~km}$ in northern Switzerland to about $60 \mathrm{~km}$ beneath the Alps in southern Switzerland (Waldhauser et al., 1998). According to Mooney et al. (1998) the northern part of our target region belongs to the 'extended crust' type which is also typical of a large part of western US and western Europe. The southern part (Swiss and French Alps) belongs to the 'orogen' type with a larger crustal thickness.

Anelastic attenuation as inferred from $\mathrm{Lg}$ wave studies in western Europe (e.g. Campillo and Plantet, 1991) shows that the attenuation in the target region lies between the values typical of active and stable regions (e.g. Singh and Herrmann, 1983; Nuttli, 1982). More recently, the Xie and Nuttli (1988) method has been applied around the world (Western US, Eastern US, Africa and Eurasia) which facilitates more stable regional comparisons (Mitchell, 1995). In Eurasia, $\mathrm{Lg}$ coda $\mathrm{Q}$ at $1 \mathrm{~Hz}$ exhibits large regional variations (Mitchell et al., 1997). Large Q values (low attenuation) are confined to portions of the East European shield, the Indian shield and western Siberia. These values are close to those found in eastern US. Low Q values (high attenuation), close to those obtained in western US, are found in the Tethyside region that extends from the southern part of western Europe, through the Middle East and Central Asia. Most of the strongmotion records used to derive European ground-motion models (Ambraseys et al., 1996; Sabetta et al., 1996; Berge-Thierry et al., 2003) have been collected in this region. The Mitchell et al. (1997) results also confirm the Campillo and Plantet (1991) results in that the French and Swiss Alpine Forelands display intermediate $\mathrm{Q}$ values.

\subsubsection{Target region site properties}

Bay et al. (2003) have found that the average site amplification in the Alpine Foreland is twice as high as in the Alps. The stations in the Alpine Foreland generally show a strong amplification and the Alpine stations show de-amplification. Alpine region rock sites are very hard rock outcrops created during glaciation in the last ice age. The reference rock velocity is chosen as $650 \mathrm{~m} / \mathrm{s}$. A large scatter of the kappa values in the target region has been demonstrated by the analysis of Rietbrock et al. (2006) in Switzerland. A reference kappa of $0.0125 \mathrm{~s}$ has been finally been chosen, for illustration purposes; the authors acknowledge that there is considerable uncertainty in this value.

\subsubsection{Host region models}

For the purpose of illustrating the parameter and hostto-target adjustments, a suite of 9 ground-motion models have been selected (Table 1). This suite was not compiled by strict application of the previously stated selection criteria, but rather to provide an illustrative set of models covering various host regions and the use of many parameter definitions. Nonetheless, the defined procedures outlined in this paper could be expected to produce a similar suite of models for the logic tree. The rigorous testing of the applicability of these 9 equations to the WCE region is outside the scope of this paper.

A first set of models is provided by European 'plate boundary related' empirical models (Sabetta and Pugliese, 1996; Ambraseys et al., 1996; BergeThierry et al., 2003). Globally based or western US 
relations provide better data quality, near source, larger magnitude coverage or better site categorization (Abrahamson and Silva, 1997; Campbell and Bozorgnia, 2003; Lussou et al., 2001; Spudich et al., 2003; Ambraseys and Douglas, 2003). Relations developed for eastern North America cannot be excluded because of low deformation rates of Central Europe. However the application of the hybrid empirical model to stochastic models such as Atkinson and Boore (1997) and Toro et al. (1997) is ill advised since in those cases one should simply generate new spectral estimates with the appropriate stochastic parameter set for the target region. To apply the hybrid empirical method to stochastically-derived equations would lead to the propagation of unnecessarily large uncertainties. Therefore, in this paper, we only discuss the treatment of empirical ground motion models. The nine candidate models are described in Table 1.

Engineering goals usually imply ground motion evaluation due to earthquakes of magnitude greater than 5. As discussed above, magnitude-distance sampling effects cannot be adjusted and therefore are one of the major selection criteria. Central Europe models based on weak motions (e.g. Malagnini et al., 2000; Bay et al., 2003; Rietbrock et al., 2006) have therefore not been selected for strong ground-motion evaluation in the present study. Such weak motion models are, however, essential for host-to-target adjustments.

The magnitude and distance applicability range of the selected models is different from the range of magnitude and distance sampled by the dataset used in the regression analysis: for example, the dataset used by Ambraseys et al. (1996) includes data from distances up to $260 \mathrm{~km}$ and magnitudes up to $\mathrm{M}_{\mathrm{S}} 7.9$; however, both of these values correspond to a single recording, with no other data at distances beyond $210 \mathrm{~km}$ and no other earthquakes of magnitude greater than $\mathrm{M}_{\mathrm{S}}$ 7.3. Analysis of the candidate models presented in Table 2 shows that some of them poorly sample large magnitude or short distances, which in a logic-tree context can be taken care of through a weighting scheme based on a binning in magnitude-distance-frequency space. The magnitude and distance validity range has been evaluated for the candidate models and is presented in Table 1.

\subsection{Selected ground-motion models adjustments}

\subsubsection{Parameter compatibility adjustments}

The candidate models (Table 1) use four different magnitude definitions, four different distance metric defini- tions and six different ways of combining the horizontal components. Median grounds motion values for frequencies of $1 \mathrm{~Hz}, 5 \mathrm{~Hz}$ and $10 \mathrm{~Hz}$ have been calculated for an earthquake of magnitude equal to 6.5 (Figure 5). For the left column in Figure 5, distances from 0 to $200 \mathrm{~km}$ are simply entered to each equation without any correction and all magnitude scales are assumed equal; for the equations that include style-of-faulting as a predictor variable, the coefficients are set to reverse rupture. Without any adjustments the differences between ground motion predictions reflects mainly the intrinsic parametric distance definitions. For example, the higher motions at short distances are predicted by models which are based on the hypocentral distance.

Parameter compatibility adjustments have then been applied to the selected ground motion models. The resulting spectral ordinates are given for an earthquake of moment magnitude $\mathrm{M}_{\mathrm{w}}=6.5$ in a JoynerBoore distance range of $0-200 \mathrm{~km}$ (central column in Figure 5). The figure shows in particular the impact of distance conversions for hypocentral distances models (Lussou et al., 2001 and Berge-Thierry et al., 2003) now predict similar values as the one of models derived in the same area (e.g. Ambraseys et al., 1996). This result confirms that of all adjustments, the distance conversion has the largest impact (this point is also discussed by Scherbaum et al., 2005). After these parametric adjustments the spread of the predictions has been strongly reduced.

\subsubsection{Full host-to-target adjustments}

In the present paper, the target region stochastic model of Bay et al. (2003) has been chosen as a reference for host-to-target adjustments. The site conversion factors have been calculated with respect to $\mathrm{V}_{\mathrm{S} 30}=650 \mathrm{~m} / \mathrm{s}$. For most of the equations in Table 1, only a range of shear-wave velocities is known for the rock class and a furthermore this range will often be a nominal range rather than the actual values encompassed by the data. Mean values and uncertainty bounds for the $\mathrm{V}_{\mathrm{S} 30}$ of each attenuation model presented Table 1 have been analyzed and are reported in Table 2.

Equivalent stochastic models for all empirical ground-motion models have been derived by Scherbaum et al. (2006). The inversion scheme used gives the opportunity to obtain stochastic model parameters for the host region even if the host empirical models have been derived with a global dataset. The description of the 9 ground-motion models stochastic parameters are given in Table 5. Figure 5 provides a fairly complete picture of the relative impact of all 
Without any conversion
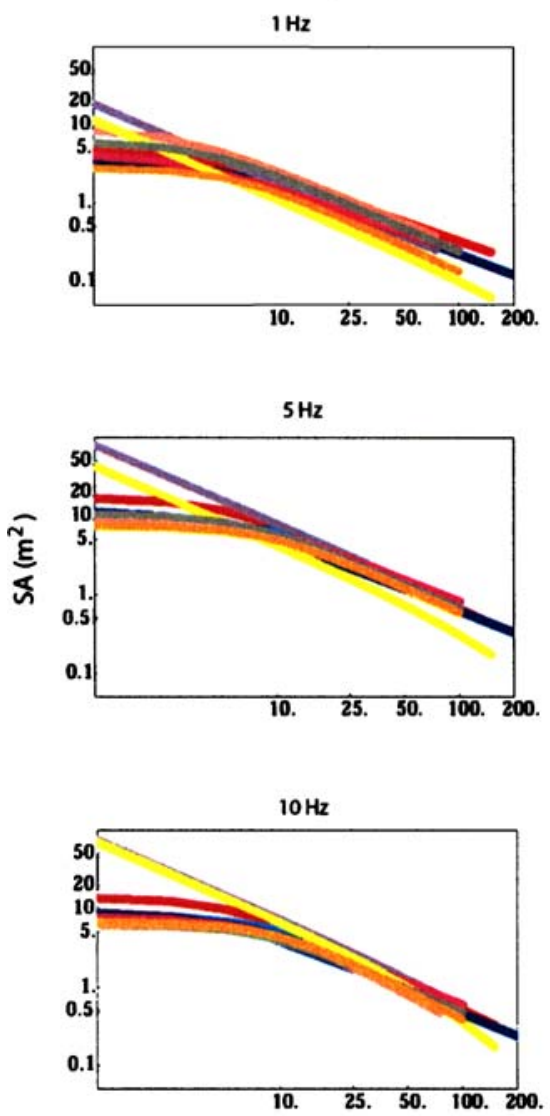

After parameter conversion
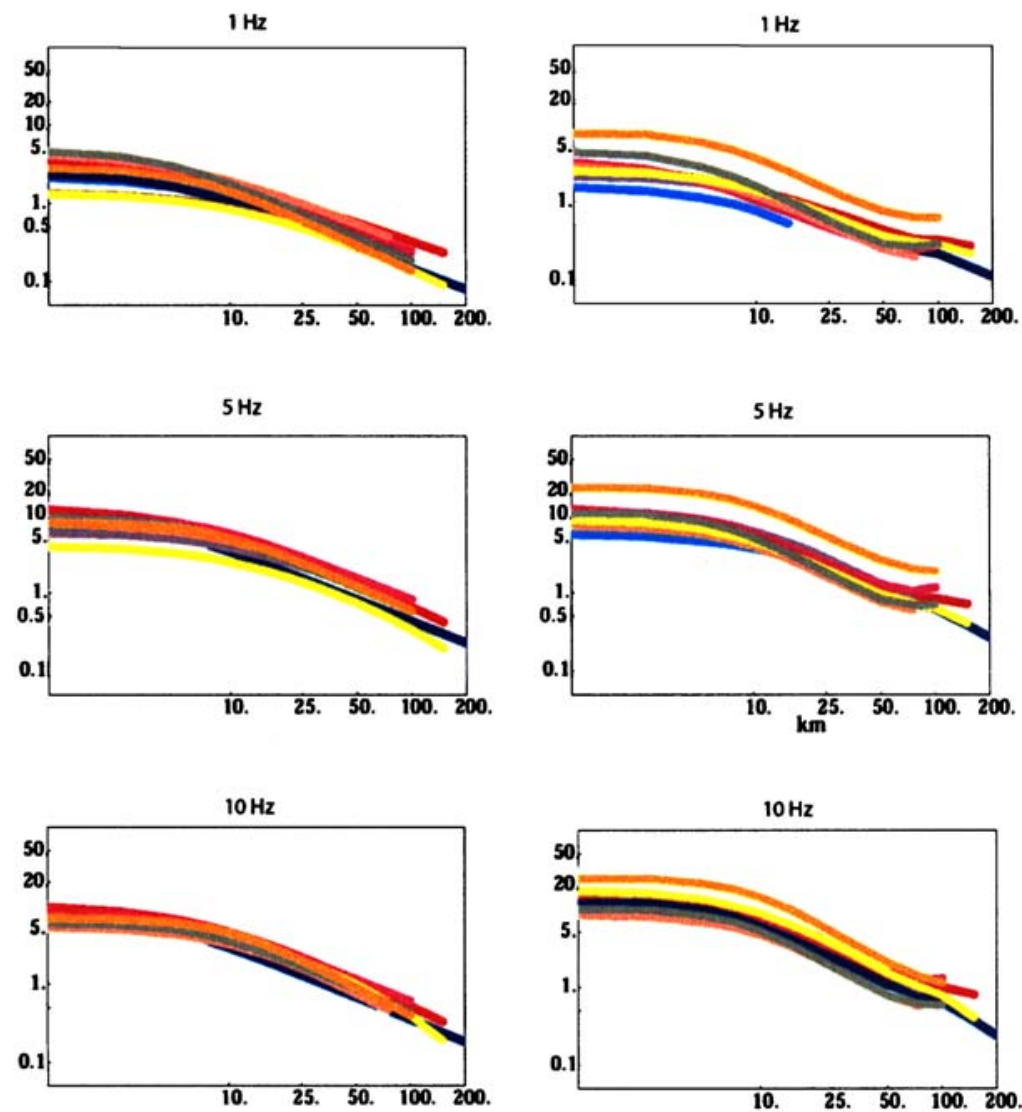

Distance, $\mathbf{k m}$

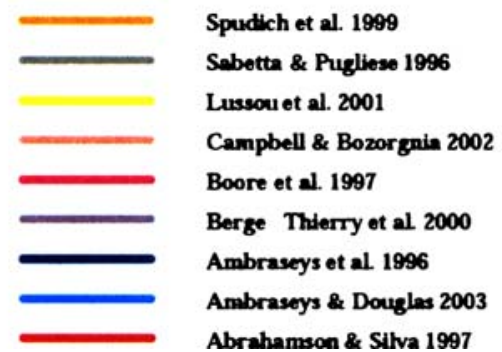

Full hybrid model
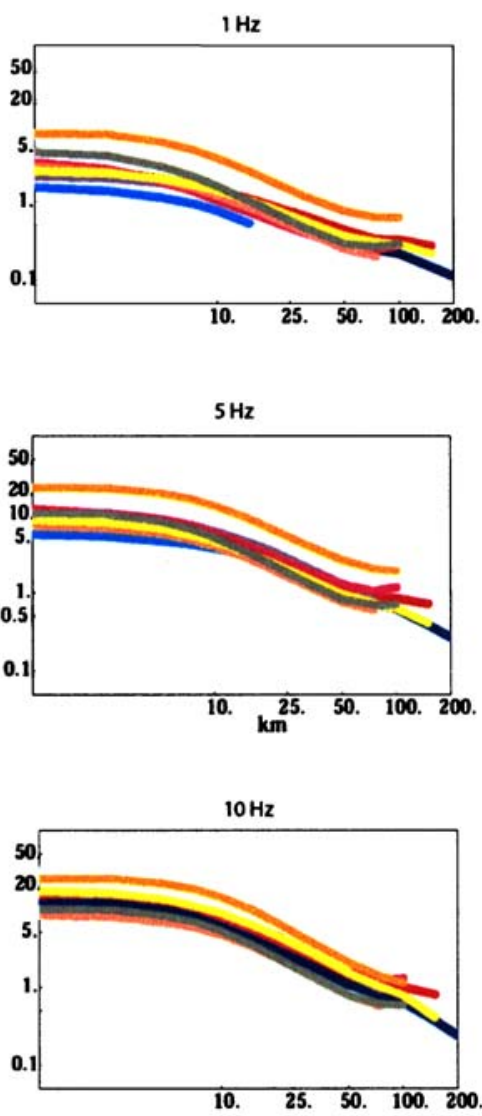

Figure 5. Median acceleration spectra $(1 \mathrm{~Hz}, 5 \mathrm{~Hz}$ and $10 \mathrm{~Hz})$ from the candidate equations for a magnitude $\mathrm{M}_{\mathrm{w}} 6.5$ earthquake (left) without adjustments, (middle) after complete parameter conversions for style-of-faulting, component, magnitude and distance conversions, and (right) after full host-to-target adjustments.

host-to-target adjustments. After these host-to-target adjustments the predicted values at $10 \mathrm{~Hz}$ are higher mainly because of the $\mathrm{V}_{\mathrm{S} 30}$ and kappa adjustments factors (Figure 4). One can notice that the Spudich et al. (1999) model now gives the higher values, which can be explained by the fact that Scherbaum et al. (2006) found that this model could not be reproduced well by a stochastic point source model.

\section{Discussion}

The seismotectonic conditions of the target region of WCE is complex, including the Alps and the Alpine Foreland, with the former being more plate boundary related and the latter more intraplate related. The selection process applied shows that the crustal conditions of this target region cannot be considered directly 
Table 5. Stochastic model parameters for the host region ground-motion models. The geometrical spreading exponent $\mathrm{a}_{3}$ up to infinity was set to $0.5, \mathrm{R}_{\Theta \phi}=0.55, V={ }^{1} / \sqrt{2}, \mathrm{~F}=2$. The density and velocity were set to $\rho_{\mathrm{s}}=2700 \mathrm{~kg} / \mathrm{m}^{3}$ and $\beta_{\mathrm{s}}=3500 \mathrm{~m} / \mathrm{s}$

\begin{tabular}{lccrcccccccc}
\hline Model name & \multirow{2}{*}{$\sigma$, bar } & $\kappa_{0}(\mathrm{sec})$ & $\mathrm{Q}_{0}$ & $\alpha$ & $\mathrm{R}_{1}(\mathrm{~km})$ & $\mathrm{a}_{1}$ & $\mathrm{R}_{2}(\mathrm{~km})$ & $\mathrm{a}_{2}$ & $\mathrm{r}$ & $V_{\mathrm{S} 30}$ & Dist \\
\hline Abrahamson and Silva, 1997 & 79 & 0.039 & 196 & 0.46 & 44.6 & -1.0 & 73.8 & -0.25 & 0.04 & 484 & ATSCA \\
Ambraseys and Douglas, 2003 & 132 & 0.039 & 52 & 0.79 & 45.6 & -0.85 & 81.1 & 0.0 & 0.02 & 646 & HYP \\
Ambraseys et al., 1996 & 18 & 0.046 & 550 & 0.49 & 10.0 & -0.8 & 68.9 & -0.95 & 0.03 & 450 & SEIS \\
Berge-Thierry et al., 2003 & 46 & 0.047 & 256 & 0.96 & 31.9 & -1.0 & 69.8 & -0.9 & 0.04 & 451 & HYP \\
Boore et al., 1997 & 77 & 0.061 & 83 & 0.06 & 49.9 & -0.8 & 83.1 & -0.3 & 0.06 & 453 & HYP \\
Campbell and Bozorgnia, 2003 & 89 & 0.051 & 166 & 0.52 & 47.3 & -0.8 & 97.8 & -0.65 & 0.03 & 532 & RRMS \\
Lussou et al., 2001 & 44 & 0.031 & 167 & 0.77 & 14.5 & -1.0 & 74.3 & -0.9 & 0.03 & 562 & HYP \\
Sabetta and Pugliese, 1996 & 56 & 0.044 & 89 & 0.99 & 44.7 & -0.8 & 102.9 & -0.7 & 0.03 & 504 & SEIS \\
Spudich et al., 1999 & 12 & 0.029 & 103 & 1.00 & 18.7 & -0.6 & 65.8 & -1.0 & 0.06 & 456 & RMS \\
\hline
\end{tabular}

equivalent to the host region properties of any of the existing strong-motion models. This in turn calls for the use of ground-motion models available for the various types of seismotectonic regimes in order to capture the epistemic uncertainty. Although applied herein specifically to the region of western Central Europe, the situation is representative of many, if not most, seismic hazard studies. The magnitude-distance sampling effects or instrumentation effects cannot be adjusted and therefore are important selection criteria, although these aspects can equally be accounted for in the weighting strategy for the logic-tree branches.

An important question that arises in such regions of low or moderate seismicity is the degree to which models derived from weak-motion data can be used for strong-motion prediction. Both the scaling of stress drops and the variation of the decay with magnitude suggest that these models could erroneously estimate the ground motions of larger earthquakes, which favors the rejection of models whose range of applicability is outside the magnitude range used for the hazard evaluation. Host region empirical model studies provide a firm basis for ground-motion estimates in areas like central Europe that are lacking the necessary strongmotion data for a purely empirical approach, provided that host-to-target conversions are applied. The sensitivity analyses performed herein show particularly the importance of distance and kappa filter corrections, if these can be applied. Host region models derived in regions with associated weak motion studies or host empirical models for which the associated stochastic models parameters have been derived have therefore to be favored in the selection.

Once the adjustments have been performed, it is important to evaluate the performance of the host-to-target region conversions. This is particularly needed since the physical basis for some of the adjustments (i.e. the kappa filter) is still a matter of debate and investigation. A rather small data set collected in the target region can help to assess the adjusted ground-motion models. The visual comparison between the observed spectral values and the model predictions provide only a qualitative visual evaluation of the fit between data and model predictions. Scherbaum et al. (2004b) show to this end how observed ground-motion records can help to guide this process in a more systematic way. A key element in this context is a new, likelihood-based, goodness-of-fit measure which has the property not only to quantify the model fit but also to measure to some degree how well the underlying statistical model assumptions are met. By design it naturally scales between 0 and 1 with a value of 0.5 for a situation in which the model perfectly matches the sample distribution both in terms of mean and standard deviation. This data driven evaluation allows to quantify the performance the groundmotion model selection and particular host-to-target region conversions.

The results of such evaluations may sometimes indicate that the host-to-target conversions have not been successful. This may occur for a number of reasons, not necessarily connected to the characterization of the target region. In Figure 5, it can be appreciated that the application of the host-to-target conversion to the equations of Spudich et al. (1999) seems to be problematic, which would partially be the result of the 'virtual' host region - encompassing a number of tectonic regimes around the world, albeit nominally united by being 'extensional' - being difficult to characterize by a single suite of representative parameters. For this reason, the authors of this paper do not recommend the 
universal and blind application of the hybrid empirical approach: the results must always be inspected and assessed.

On the same issue of the host-to-target adjustments, it is also important to acknowledge that the procedures presented in this paper have not included consideration of the uncertainty on the ground-motion variability due to the host-to-target conversions. The effect could be to reduce the sigma values of some models in some situations and to increase the scatter in others; this is an area requiring investigation.

Another aspect that has not been considered in this study, and which could well prove very useful for the selection of appropriate ground-motion models, is the possibility of using intensity attenuation characteristics as an analogy in the selection of ground-motion models. Correlations between macroseismic intensities and instrumental ground-motion parameters exist but mostly concern active regions like western United States (e.g. Wald et al., 1999; Atkinson and Sonley, 2000; Kaka and Atkinson, 2004) and generally have very large associated scatters. Such information is, however, a significant source of information to be used in order to validate (at least qualitatively) the characteristization of regional attenuation. Analysis of intensity attenuation versus distance in central Europe (e.g. Rüttener, 1995), for example, leads to the definition of distinct regions with different attenuation properties. The highest attenuation is observed in the sub-Alpine chains (Helvetic and Ultrahelvetic nappes) and the lowest in the crystalline basement and Pennic nappes of the Alps. Macroseismic data therefore confirms that the crustal properties of the WCE target region are complex and that ground-motion models available for various types of seismotectonic regimes are needed to capture the epistemic uncertainty.

\section{Conclusions}

Most seismic hazard analyses, especially if one considers the number of people exposed to the associated seismic risk, are performed for locations outside the few regions of the world (essentially California and Japan) with abundant strong-motion data and indigenous ground-motion prediction equations. Since there will rarely be a clearly analogous region to the one under study from which ground-motion models can simply be borrowed, most hazard analysts are faced with the difficult question of selecting appropriate equations to be used in the calculations. The analyst will generally select two or more equations in order to take account of the epistemic uncertainty in both the median estimates and the aleatory variability (sigma values) of the models in terms of their applicability to the target region.

Hazard analyses employing multiple groundmotion models generally make use of logic trees. Reports and papers on hazard studies often focus on the weighting strategy applied to the logic-tree branches, conveying the impression that the selection of the candidate models to populate the logic tree in the first place is relatively unimportant. It has been shown recently that the selection of ground-motion models is vitally important and generally exerts a much greater influence on the hazard results than the details of the weighting scheme (Sabetta et al., 2005). To this end this paper attempts to provide some clear guidelines that analysts may follow for the selection of ground-motion models to be used in a logic tree, instead of the rather vague procedures often employed in current practice, whereby an analyst's choice is governed by familiarity with certain models, regions and ground-motion modelers.

The guidelines proposed herein for model selection effectively oblige the analyst to begin by becoming familiar with the full suite of models available globally and then to reduce this list by a process of objective evaluation. The authors feel that the use of regional weak-motion data for strong-motion prediction is still an open issue. We rather suggest to select empirical strong ground-motion models and to correct these models for systematic differences between host and target regions using the hybrid empirical method (Campbell, 2003; Scherbaum et al., 2005).

\section{Acknowledgements}

This paper is contribution EG2/DT-05 from a series of studies inspired by participation in the PEGASOS project (Abrahamson et al., 2002). We thank the following people for providing a stimulating environment and continuous support for the development of ideas presented herein: Norm Abrahamson, Philip Birkhauser, Jim Farrington, Andreas Hölker, Philippe Roth, Patrick Smit and Christian Sprecher. We also acknowledge the benefit derived from our many discussions with Fabio Sabetta on these issues throughout the course of the project. We also would like to give a special mention to Ms Anna Hikel for taking care of us and supplying us with excellent coffee during long working sessions at Imperial College London. F.C. benefited from the 
support of the INSU Program "ACI Risques Naturels

et Changements Climatiques.

\section{References}

Abercrombie, R.E., 1995, Earthquake source scaling relationships from -1 to $5 \mathrm{M}_{\mathrm{L}}$ using seismograms recorded at $2.5 \mathrm{~km}$ depth, $J$. Geophys. Res. 100, 24015-24036.

Abrahamson, N.A. and Bommer, J.J., 2005, Probability and uncertainty in seismic hazard analysis, Earthquake Spectra 21(2), 603607.

Abrahamson, N.A., Birkhauser, P., Koller, M., Mayer-Rosa, D., Smit, P.M., Sprecher, C., Tinic, S. and Graf, R., 2002, PEGASOS- A comprehensive probabilistic seismic hazard assessment for nuclear power plants in Switzerland, Proceedings of the Twelfth European Conference on Earthquake Engineering, Paper no 633, London.

Abrahamson, N.A. and Shedlock, K.M., 1997, Overview. Seism. Res. Lett. 68(1), 9-23.

Abrahamson, N.A. and Silva, W.J., 1997, Empirical response spectral attenuation relations for shallow crustal earthquakes, Seism. Res. Lett. 68, 94-127.

Aki, K., 1966, Generation and propagation of $\mathrm{G}$ waves from the Niigata earthquake of June, 1964, Part 2: Estimation of earthquake moment, from the $\mathrm{G}$ wave spectrum, Bull. Earthquake Res. Inst. Tokyo Univ. 44, 73-88.

Ambraseys, N.N. and Douglas, J., 2003, Near-field horizontal and vertical ground motion relations, Soil Dyn. Earthquake Eng. 23, $1-18$.

Ambraseys, N.N., Douglas, J., Smit, P. and Sarma, S.K., 2005, Equations for the estimation of strong ground motions from shallow crustal earthquakes using data from Europe and the Middle East: Horizontal peak ground acceleration and spectral acceleration, Bull. Earthquake Eng. 3(1), 1-53.

Ambraseys, N.N., Simpson, K.A. and Bommer, J.J., 1996, Prediction of horizontal response spectra in Europe, Earth. Eng. Struct. Dyn. 25, 371-400.

Anderson, J.G., 2000, Expected shape of regressions for groundmotion parameter on rock, Bull. Seim. Soc. Am. 90(6B), S42-S52.

Anderson, J.G. and Hough, S.E., 1984, A model for the shape of the Fourier amplitude spectrum of acceleration at high frequencies, Bull. Seism. Soc. Am. 74(5), 1969-1993.

Atkinson, G.M., 1993, Earthquake source spectra in eastern North America, Bull. Seism. Soc. Am. 83, 1778-1798.

Atkinson, G.M., 1996, The high frequency shape of the source spectrum for earthquakes in eastern and western Canada, Bull. Seism. Soc. Am. 86, 106-112.

Atkinson, G.M. and Boore, D.M., 1988, Evaluation of models for earthquake source spectra in Eastern North America, Bull. Seism. Soc. Am. 88, 917-934.

Atkinson, G.M. and Boore, D.M., 1997, Some comparisons between recent ground-motion relations, Seism. Res. Lett. 68, 24-40.

Atkinson, G.M. and Boore, D.M., 2000, Reply to Comment on "Evaluation of models for earthquake source spectra in eastern North America by Gail M. Atkinson and David M. Boore, Bull. Seism. Soc. Am. 90, 1339-1341.

Atkinson, G.M. and Boore, D., 2003, Empirical ground-motion relations for subduction zone earthquakes and their application to
Cascadia and other regions, Bull. Seism. Soc. Am. 93(4), 17031729.

Atkinson, G.M. and Sonley, E., 2000, Empirical relationships between modfied Mercalli intensity and response spectra, Bull Seism. Soc. Am. 90, 537-544.

Bard, P.Y. and Riepl-Thomas, J., 1999, Wave propagation in complex geological structures and local effects on strong motion, In: E. Kausel and G.D. Manolis (eds.), Wave motion in earthquake engineering, Advances in Earthquake Engineering, WIT Press, pp. 38-95.

Bay, F., Fäh, D., Malagnini, L. and Giardini, D., 2003, Spectral shearwave ground motion scaling in Switzerland, Bull. Seism. Soc. Am. 93, 414-429.

Berge-Thierry, C., Cotton, F., Scotti, O., Griot-Pommera, D.A. and Fukushima, Y., 2003, New empirical response spectral attenuation laws for moderate European earthquakes, J. Earthquake Eng. 7, 193-222.

Beyer, K. and Bommer, J.J., 2005, Relationships between median values and aleatory variabilities for different definitions of the horizontal component of motion, submitted to Bull. Seism. Soc. Am.

Boatwright, J., Choy, G.L. and Seekins, L.C., 2002, Regional estimates of radiated seismic energy, Bull. Seism. Soc. Am. 92, 12411255.

Bommer, J.J., Douglas, J. and Strasser, F.O., 2003, Style-of-faulting in ground-motion prediction equations, Bull. Earthquake Eng. 1(2), 171-203.

Bommer, J.J., Scherbaum, F., Bungum, H., Cotton, F. and Sabetta, F., 2005, On the use of logic trees for ground-motion prediction equations in seismic hazard analysis, Bull. Seism. Soc. Am. 95(2), 377-389.

Boore, D.M., 1983, Stochastic simulation of high frequency ground motion based on seismological models of the radiated spectra, Bull. Seism. Soc. Am. 73, 1865-1894.

Boore, D.M., 2003, SMSIM-Fortran programs for simulating ground motions from earthquakes: Version 2.0-A revision of OFR 96-80A, USGS.

Boore, D.M., 2003a, Simulation of ground motion using the stochastic method, Pure Appl. Geophys. 160, 635-676.

Boore, D.M., 2003b, SMSIM-Fortran programs for simulating ground motions from earthquakes: version 2.0-A revision of OFR 96-80-A, USGS.

Boore, D.M. and Bommer, J.J., 2005, Processing strong-motion accelerograms: Needs, options and consequences, Soil Dyn. Earthquake Eng. 25, 93-115.

Boore, D.M. and Joyner, W.B., 1984, A note on the use of random vibration theory to predict peak amplitudes of transient signals, Bull. Seism. Soc. Am. 74(5), 2035-2039.

Boore, D.M. and Joyner, W.B., 1997, Site amplifications for generic rock sites, Bull. Seism. Soc. Am. 87(2), 327-341.

Boore, D.M., Joyner, W.B. and Fumal, T.E., 1997, Equations for estimating horizontal response spectra and peak acceleration from Western North American earthquakes: A summary of recents work, Seism. Res. Lett. 68(1), 128-153.

Bragato, L. and Slejko, D., 2005, Empirical ground-motion attenuation relations for the eastern Alps in the magnitude range 2.5-6.3, Bull. Seism. Soc. Am. 95(1), 252-276.

Brodsky, E.E. and Kanamori, H., 2001, The elastohydrodynamic lubrication of faults, J. Geophys. Res. 106, 16357-16374.

Brune, J.N., 1970, Tectonic stress and seismic shear waves from earthquakes, J. Geophys. Res. 75, 4997-5009. 
Brune, J.N., 1971, Correction, J. Geophys. Res. 76, 5002.

Budnitz, R.J., Apostolakis, G., Boore, D.M., Cluff, L.S., Coppersmith, K.J., Cornell, C.A. and Morris, P.A., 1997, Recommendations for probabilistic seismic hazard analysis: guidance on uncertainty and use of experts. NUREG/CR-6372.

Campbell, K.W., 2003, Prediction of strong ground motion using the hybrid empirical method and its use in the development of ground motion (attenuation) relations in eastern North America, Bull. Seism. Soc. Am. 93, 1012-1033. Erratum: vol 94, p2418.

Campbell, W. and Bozorgnia, Y., 2003, Updated near source ground motion relations for horizontal and vertical components of peak ground acceleration, peak ground velocity and pseudo-absolute acceleration response spectra, Bull Seism. Soc. Am. 93, 314-331, Errata: vol93 p 1413, vol 94 p 2417.

Campillo, M. and Plantet, J.L., 1991, Frequency dependence and spatial distribution of seismic attenuation in France: experimental results and possible interpretations, Phys. Earth and Planet. Int. 67, 48-64.

Douglas, J., 2003, Earthquake ground motion estimation using strong-motion records: a review of equations for the estimation of peak ground acceleration and response spectra ordinates, Earth Science Review 61, 43-104.

Ferry, M., Meghraoui, M., Delouis, B. and Giardini, D., 2005, Evidence of Holocene palaeoseismicity along the Basel-Reinach active normal fault (Switzerland): a seismic source for the 1356 earthquake in the Upper Rhine graben, Geophys J. Int. 160, 554-572.

Frankel, A., McGarr, A., Bicknell, J., Mori, J., Seeber, L. and Cranswick, E., 1990, Attenuation of high-frequency shear waves in the crust: Measurements from New York state, South Africa and southern California, J. Geophys. Res. 95(B11), 17441-17457.

Fukushima, Y. and Tanaka, T., 1990, A new attenuation relation for peak horizontal acceleration of strong earthquake ground motion in Japan, Bull. Seism. Soc. Am. 80, 757-783.

Gulkan, P. and Kalkan, E., 2002, Attenuation modelling of recent earthquakes in Turkey, J. Seism. 6(3), 397-409.

Haddon, R.A.W., 1996, Earthquake source spectra in Eastern North America, Bull. Seism. Soc. Am. 86, 1300-1313.

Haddon, R.A.W., 1997, Reply to Comments by G.M. Atkinson, et al. on 'Earthquake source spectra in eastern North America,' Bull. Seism. Soc. Am. 87, 1703-1708.

Haddon, R.A.W., 2000, Comment on "Evaluation of models for earthquake source spectra in eastern North America" by Gail M. Atkinson and David M. Boore, Bull. Seism. Soc. Am. 90, 1332-1338.

Hanks, T., 1982, fmax, Bull. Seism. Soc. Am. 72, 1867-1879.

Herrmann, R.B. and Kijko, A., 1983, Modeling some empirical component Lg relations, Bull. Seism. Soc. Am. 73, 157-171.

Ide, S. and Beroza, G.C., 2001, Does apparent stress vary with earthquake size? Geophys, Res. Lett. 28(17), 3349-3352.

Izutani, Y. and Kanamori, H., 2001, Scale dependence of seismic energy-to-moment ratio for strike-slip earthquakes in Japan, Geophys. Res. Lett. 28, 4007-4010.

Joyner, W.B. and Boore, D.M., 1981, Peak horizontal acceleration and velocity from strongmotion records including records from the 1979 Imperial Valley, California, earthquake, Bull. Seism. Soc. Am. 71(6), 2011-2038.

Kaka, S.I. and Atkinson, G.M., 2004, Relationships between instrumental ground-motion parameters and modified Mercalli intensity in Eastern North-America, Bull. Seism. Soc. Am. 94(5), 1728-1736.
Kanamori, H. and Anderson, D.L., 1975, Theoretical basis of some empirical relations in seismology, Bull. Seism. Soc. Am. 65(5), 1073-1095.

Kanamori, H. and Heaton, T., 2000, Microscopic and macroscopic mechanism of earthquakes, In: D.L.T.a.W.K. J. Rundle (Editor), Geocomplexity and Physics of Earthquakes, American Geophysical Monograph, pp. 147-163.

Kanamori, H. and Rivera, L., 2004, Static and dynamic scaling relations for earthquakes and their implication for rupture speed and stress drop, Bull. Seism. Soc. Am. 94, 314-319.

Kulkarni, R.B., Youngs, R.R. and Coppersmith, K.J., 1984, Assessment of confidence intervals for results of seismic hazard analysis, Proceedings of the Eighth World Conference on Earthquake Engineering, San Francisco, pp. 263-270.

Lussou, P., Fukushima, Y., Bard, P.Y. and Cotton, F., 2001, Seismic design regulation codes: contribution of Knet data to site effect evaluation, J. Earthquake Eng. 5(1), 13-33.

Malagnini, L., Herrmann, R.B. and Koch, K., 2000, Regional ground-motion scaling in central Europe, Bull. Seism. Soc. Am. 90(4), 1052-1061.

Mayeda, K. and Walter, W.R., 1996, Moment, energy, stress drop and source spectra of western United State earthquakes from regional code envelopes, J. Geophys. Res. 101, 11195-11208.

McGarr, A. and Fletcher, J.B., 2002, Mapping apparent stress and energy radiation over fault zones of major earthquakes, Bull. Seism. Soc. Am. 92, 1633-1646.

McGuire, R.K., Cornell, C.A. and Toro, G.R., 2005, The case of using mean seismic hazard, Earthquake Spectra, 21(3), 879886.

Mitchell, B.J., 1995, Anelastic structure and evolution of the continental crust and upper mantle from seismic surface wave attenuation, Rev. Geophys. 33, 441-462.

Mitchell, B.J., Pan, Y.P., Xie, J. and Cong, L., 1997, Lg coda Q variation across Eurasia and its relation to crustal evolution, $J$. Geophys. Res 102, 22767-22779.

Musson, R.M.W., 2005, Against fractiles, Earthquake Spectra 21(3), 887-891.

Mooney, W.D., Laske, G. and Masters, T.G., 1998, CRUST 5.1: A global crustal model at $5^{\circ} \times 5^{\circ}, J$. Geophys. Res 103(B1), 727-747.

Nocquet, J.M. and Calais, E., 2003, Crustal velocity field of western Europe from permanent GPS array solutions, 1996-2001, Geophys. J. Int. 154, 72-88.

Nuttli, O., 1982, The earthquake problem in the eastern United States, J. Struct. Div. Soc. Eng. 108, 1302-1312.

Oye, V., Bungum, H. and Roth, M., 2005, Source parameters and scaling relations for mining related seismicity with the Pyhäsalmi ore mine, Finland, Bull. Seism. Soc. Am. 95(3), 1011-1026.

Özbey, C., Sari, A., Manuel, L., Erdik, M. and Fahjan, Y., 2004, An empirical attenuation relationship for northwestern Turkey ground motion using a random effects approach, Soil Dyn. Earthquake Eng. 24, 115-125.

Papageorgiou, A.S. and Aki, K., 1983, A specific barrier model for the quantitative description of inhomogeneous faulting and the prediction of strong ground motion, Bull. Seism. Soc. Am. 73(4), 693-722.

Raoof, M., Herrmann, R.B. and Malagnini, L., 1999, Attenuation and excitation of three-component ground motion in Southern California, Bull. Seism. Soc. Am. 89(4), 888-902.

Reiter, L., 1990, Earthquake Hazard Analysis: Issues and Insights, Columbia University Press, New York, Oxford. 
Rey, J., Faccioli, E. and Bommer, J.J., 2002, Derivation of design soil coefficients (S) and response spectral shapes for Eurocode 8 using the European Strong-Motion Database, J. Seismol. 6, 547-555.

Rietbrock, A., 2001, P wave attenuation structure in the fault area of the 1995 Kobe earthquake, J. Geophys. Res. 106(B3), 41414154.

Rietbrock, A., Scherbaum, F., Cotton, F. and Fäh, D., 2006, On the determination of source, path, and site effects from microearthquake recordings for strong ground motion prediction, in revision to Bull. Seism. Soc. Am.

Rüttener, 1995, Earthquake hazard evaluation for Switzerland, Géol. Suisse, Nr29, Schweizerische Geophysikalische Kommission, ETH-Zürich, 106.

Sabetta, F., Lucantoni, A., Bommer, J.J. and Bungum, H., 2005, Sensitivity of PSHA results to ground-motion prediction relations and logic-tree weights, Soil Dyn. Earthquake Eng. 25(4), 317-329.

Sabetta, F. and Pugliese, A., 1996, Estimation of ground motion and simulation of Nonstationary earthquake ground motions, Bull. Seism. Soc. Am. 86, 337-352.

Scherbaum, F., 1990, Combined inversion for the three-dimensional Q structure and source parameters using microearthquake spectra, J. Geophys. Res 95(B8), 12423-12438.

Scherbaum, F., Schmedes, J. and Cotton, F., 2004a, On the conversion of source-to-site distance measures for extended earthquake source model, Bull. Seism. Soc. Am. 94, 1053-1059.

Scherbaum, F., Cotton, F. and Smit, P., 2004b, On the use of response spectral reference data for the selection of ground-motion models for seismic hazard analysis: the case of rock motion, Bull. Seism. Soc. Am. 94(6), 1-22.

Scherbaum, F., Bommer, J.J., Bungum, H., Cotton, F. and Abrahamson, N.A., 2005, Composite ground-motion models and logic trees: methodology, sensitivities and uncertainties, Bull. Seism. Soc. Am. 95(5), 1575-1593.

Scherbaum, F., Cotton, F. and Staedtke, H., 2006, The estimation of minimum-misfit stochastic models from empirical ground-motion equations, Bull. Seim. Soc. Am., in press.

Scholz, C.H., 1994, Reply to comments on 'A reappraisal of large earthquake scaling', Bull. Seism. Soc. Am. 84, 1677-1678.

Scholz, C.H., Aviles, C.A. and Wesnousky, S.G., 1986, Scaling differences between large interplate and intraplate earthquakes, Bull. Seism. Soc. Am. 76(1), 384-397.

Silva, W., Darragh, D., Gregor, N., Martin, G., Abrahamson, N. and Kircher, C., 2000, Reassessment of site coefficients and near fault factors for building code provisions, Program Element: II, 98-HQ-GR-1010. Report to USGS.
Singh, S.K. and Herrmann, R.B., 1983, Regionalization of crustal coda Q in the continental United States, J. Geophys. Res. 88, 527-538.

Somerville, P.G., McLaren, J.P., Saikia, C.K. and Helmberger, D.V., 1990, The 25 November 1988 Saguenay, Quebec, earthquake: source parameters and the attenuation of strong ground motion, Bull. Seism. Soc. Am. 80(5), 1118-1143.

Spudich, P., Joyner, W.B., Lindh, A.G., Boore, D.M., Margaris, M. and Fletcher, J.B., 1999, SEA99: A revised ground motion prediction relation for use in extensional tectonic regimes, Bull. Seism. Soc. Am. 89, 1156-1170.

Stepp, J.C., Wong, I., Whitney, J., Quittemeyer, R., Abrahamson, N., Toro, G., Youngs, R., Coppersmith, K., Savy, J. and Sullivan, T., 2001, Probabilistic seismic hazard analyses for ground motions and fault displacements at Yucca Mountain, Nevada, Earthquake Spectra 17(1), 113-151.

Toro, G.R., Abrahamson, N.A. and Schneider, J.F., 1997, Model of strong ground motions for earthquakes in central and eastern north-america, Seism. Res. Lett. 68, 41-57.

Venkataraman, A., Rivera, L. and Kanamori, H., 2002, Radiated energy from the October 16, 1999 Hector Mine earthquake: regional and teleseismic estimates, Bull. Seism. Soc. Am. 92, 12561265.

Vigny, C., Chery, J., Duquesnoy, T., Jouanne, F., Amman, J., Andizei, M., Avouac, J.P., Barlier, F., Bayer, R., Briole, P., Calais, E., Cotton, F., Duquenne, F., Feigl, K., Ferhat, G., Flouzat, M., Gamont, J.F., Geiger, A., Harmel, A., Kasser, M., Laplanche, M., LePape, M., Martinet, J., Menard, G., Meyer, B., Ruegg, J.C., Scheubel, J.M., Scotti, O. and Vidal, G., 2002, GPS network monitor the western Alps deformation over a five year period, 93-98, Journal of Geodesy 76, 63-76.

Wald, D.J., Quitoriano, V., Heaton, T.H. and Kanamori, H., 1999, Relationships between peak ground acceleration, peak ground velocity, and modified Mercalli intensity in California, Earthquake Spectra 15(3), 557-564.

Waldhauser, F., Kissling, J., Ansorge, J. and Mueller, S., 1998, Three-dimensional interface modelling with two-dimensional seismic data: The Alpine crust-mantle boundary, Geophys. J. Int. 135, 264-278.

Wyss, M. and Brune, J.N., 1968, Seismic moment, stress and source dimensions for earthquakes in the California-Nevada region, $J$. Geophys. Res. 73, 4781-4694.

Xie, J. and Nuttli, O.W., 1998, Interpretation of high frequency coda at large distances: Stochastic modeling and method of inversion, Geophys. J. Int. 95, 579-595. 